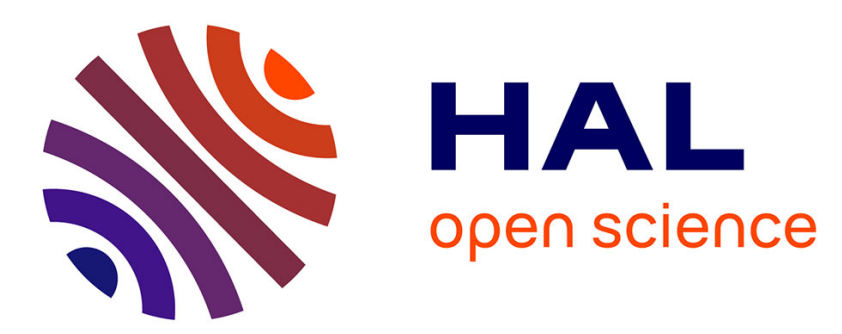

\title{
Structural characterization of Fe-C coatings prepared by reactive triode-magnetron sputtering
}

Isabelle Jouanny, Valérie Demange, Jaafar Ghanbaja, Elizabeth Bauer-Grosse

\section{To cite this version:}

Isabelle Jouanny, Valérie Demange, Jaafar Ghanbaja, Elizabeth Bauer-Grosse. Structural characterization of $\mathrm{Fe}-\mathrm{C}$ coatings prepared by reactive triode-magnetron sputtering. Journal of Materials Research, 2010, 25 (9), pp.1859-1869. 10.1557/JMR.2010.0241 . hal-00829922

\section{HAL Id: hal-00829922 \\ https://hal.science/hal-00829922}

Submitted on 4 Jun 2013

HAL is a multi-disciplinary open access archive for the deposit and dissemination of scientific research documents, whether they are published or not. The documents may come from teaching and research institutions in France or abroad, or from public or private research centers.
L'archive ouverte pluridisciplinaire HAL, est destinée au dépôt et à la diffusion de documents scientifiques de niveau recherche, publiés ou non, émanant des établissements d'enseignement et de recherche français ou étrangers, des laboratoires publics ou privés. 


\title{
Structural characterization of $\mathrm{Fe}-\mathrm{C}$ coatings prepared by reactive triode-magnetron sputtering
}

\author{
Isabelle Jouanny \\ Institut Jean Lamour, UMR 7198 CNRS-Nancy-Université-UPV-Metz, Ecole des Mines de Nancy, \\ 54042 Nancy Cedex, France \\ Valérie Demange ${ }^{\text {a) }}$ \\ Sciences Chimiques de Rennes UMR 6226 CNRS-Université Rennes 1, Campus de Beaulieu, \\ 35042 Rennes Cedex, France \\ Jaafar Ghanbaja \\ Institut Jean Lamour, UMR 7198 CNRS-Nancy-Université-UPV-Metz, Ecole des Mines de Nancy, \\ 54042 Nancy Cedex, France; and Service Commun de Microscopies Electroniques et Microanalyses X, \\ 54506 Vandoeuvre-Lès-Nancy, France \\ Elisabeth Bauer-Grosse \\ Institut Jean Lamour, UMR 7198 CNRS-Nancy-Université-UPV-Metz, Ecole des Mines de Nancy, \\ 54042 Nancy Cedex, France
}

(Received 16 December 2010; accepted 19 April 2010)

\begin{abstract}
$\mathrm{Fe}_{1-x} \mathrm{C}_{x}$ coatings were synthesized by triode magnetron sputtering of an iron target in a methane/argon atmosphere with a large range of composition ( $x=0.3$ to $0.6 \pm 0.06)$. Film surfaces were characterized by grazing incidence $x$-ray diffraction, scanning and transmission electron microscopies, and electron energy loss spectroscopy, to study effects of the variation of the methane gas flow rate on their structural properties. The coatings were constituted of the $\varepsilon-\mathrm{Fe}_{3} \mathrm{C}$ carbide $(x=0.3$ and 0.36$)$, in which carbon atoms are in octahedral sites, and of nanocomposite structure constituted of disordered and crystalline carbide nanograins embedded in a carbon matrix made of an amorphous and poorly crystallized graphenelike material ( $x=0.55$ and 0.60$)$. In situ annealing of the nanocomposite $\mathrm{Fe}_{0.45} \mathrm{C}_{0.55}$ coating led to the formation of carbides $\theta-\mathrm{Fe}_{3} \mathrm{C}$ and $\mathrm{Fe}_{7} \mathrm{C}_{3}$ (with carbon atoms in prismatic sites) and $\mathrm{C}$-rich cubic carbide possibly related to the $\tau_{2}-\mathrm{Fe}_{2} \mathrm{C}_{7}$ compound.
\end{abstract}

\section{INTRODUCTION}

Iron carbides have been intensively studied over the past several decades due to their mechanical, tribological, and magnetic properties. ${ }^{1-3}$ For several years, iron/carbon and iron carbides/carbon composite materials have also presented a strong interest for their magnetic properties like giant magnetoresistance for recording media applications. $^{4-6}$ In these materials, ferromagnetic particles are embedded in carbon, which provides protection against outside degradation like oxidation or corrosion, and magnetic insulation between particles. ${ }^{4,6}$ Sputtering of a composite target in a neutral atmosphere, or of a metallic target in a reactive atmosphere, is a powerful process to produce metal/nonmetal films with a large range of composition. ${ }^{7}$ New iron carbon materials can be synthesized by this technique. As-sputtered states and film composition are strongly dependent on the elaboration parameters, like substrate temperature, working pressure, or composi-

\footnotetext{
a) Address all correspondence to this author. e-mail: valerie.demange@univ-rennes1.fr DOI: $10.1557 / J M R .2010 .0241$
}

tion of the composite target. Therefore, crystalline phases, like $\alpha-\mathrm{Fe}(\mathrm{C}), \varepsilon-\mathrm{Fe}_{3} \mathrm{C}, \theta-\mathrm{Fe}_{3} \mathrm{C}$, or $\chi-\mathrm{Fe}_{5} \mathrm{C}_{2}$ compounds, ${ }^{3,8,9}$ amorphous ${ }^{3}$ or composite films can be prepared with the possibility to act on their structuration.

Kazama et al. ${ }^{10}$ first reported the formation of amorphous $\mathrm{Fe}_{1-x} \mathrm{C}_{x}$ films $(0.25 \leq x \leq 0.50)$ deposited by conventional diode sputtering of $\mathrm{Fe}_{2} \mathrm{C} / \mathrm{Fe}_{3} \mathrm{C}$ targets under variable $\mathrm{Ar}$ pressures at room temperature. BauerGrosse and Le Caer ${ }^{11}$ obtained a set of $\mathrm{Fe}_{1-x} \mathrm{C}_{x}$ films by triode sputtering of composite targets keeping constant all the other deposition parameters: for $x \leq 0.19$, films consisted of a mixture of amorphous $\mathrm{Fe}-\mathrm{C}$ zones and $\mathrm{Fe}$ rich zones; for $0.19 \leq x \leq 0.32$, films were single-phased amorphous, and for $0.32 \leq x$, they were a mixture of amorphous $\mathrm{Fe}-\mathrm{C}$ zones and amorphous $\mathrm{C}$-rich zones. It was indirectly shown that, with increasing of $x$, the $\mathrm{Fe}-\mathrm{C}$ zones kept a carbon content of $\sim 0.32$, but their size decreased (2000 nm for $x=0.32$ to $50 \mathrm{~nm}$ for $x=0.45$ ), indicating the possibility to produce $\mathrm{Fe}-\mathrm{C}$ nanocomposites by nanostructuration of the two amorphous phases. Afterwards, nanocomposite $\mathrm{Fe}_{1-x} \mathrm{C}_{x}(0.26 \leq x \leq 0.88)$ thin films were effectively elaborated by ion-beam 
sputtering of an iron-graphite composite $\operatorname{target}^{6,12}$ : $\mathrm{Fe}_{0.74} \mathrm{C}_{0.26}$ film, prepared at room temperature, was composed of $\mathrm{Fe}$-rich connected nanograins surrounded by amorphous-like carbon, while films of composition $\mathrm{Fe}_{0.46} \mathrm{C}_{0.54}$ and $\mathrm{Fe}_{0.26} \mathrm{C}_{0.74}$ deposited at 573 and $773 \mathrm{~K}$, respectively, consisted of spherical and well-separated $\alpha$-Fe nanoparticles embedded in poorly crystallized graphite-like carbon layers. Lee et al. ${ }^{13}$ have also obtained nanocomposite films by sputtering of a composite target: the nanograins, embedded in an amorphous carbon matrix, were either $\mathrm{Fe} / \theta-\mathrm{Fe}_{3} \mathrm{C}$ or only $\theta-\mathrm{Fe}_{3} \mathrm{C}$ carbide according to the film composition $(0.42 \leq x \leq 0.85)$.

Sputtering of a metallic target in a reactive atmosphere containing methane is therefore of a strong interest because the control of the gas ratio $\mathrm{CH}_{4} / \mathrm{Ar}$ allows the control of the film structure and composition ${ }^{14}$ in a more flexible way than the use of composite target. It was shown in a previous work that the global carbon content $(x)$ in films measured by energy dispersive spectroscopy (EDS) was proportional to the methane partial pressure and that films become $\mathrm{x}$-ray amorphous with the increase of $x{ }^{15}$

This work deals with the evolution of structural properties of the $\mathrm{Fe}-\mathrm{C}$ film surfaces with the control of the gas ratio $\mathrm{CH}_{4} / \mathrm{Ar}$. Grazing incidence $\mathrm{x}$-ray diffraction (GIXRD), scanning electron microscopy (SEM), transmission electron microscopy (TEM), and electron energy loss spectroscopy (EELS) were used for this purpose. A thermal in situ treatment study in the TEM was also performed on one of the richest carbon samples.

\section{EXPERIMENTAL SECTION}

\section{A. Synthesis}

Four $\mathrm{Fe}_{1-x} \mathrm{C}_{x}$ films (denoted hereafter $\mathrm{A}, \mathrm{B}, \mathrm{C}$, and $\mathrm{D}$, see Table I) were deposited on copper substrates at $373 \mathrm{~K}$ by direct current (dc) sputtering of an iron target $(50 \mathrm{~mm}$ in diameter, $1 \mathrm{~mm}$ thick, $99.5 \%$ purity) in a specific configuration detailed in Ref. 15 under argon/methane reactive mixtures. Before elaboration, the substrates were polished and heated in carbon tetrachloride until boiling, and then cleaned ultrasonically in an ethanol bath. The experimental sputtering device was a $30-\mathrm{L}$ sputtering chamber equipped with a magnetron target substrate holder parallel to the substrate. A base vacuum of about $10^{-4} \mathrm{~Pa}$ was ensured by a secondary suction system composed of primary and secondary oil diffusion pumps.
The gas flow rates were controlled by digital MKS flowmeters (MKS Instruments, Inc., Andover, MA). They were kept constant at 30 standard cubic centimeters per minute (sccm) for Ar and regulated at 2.5, 5, 7.5, and $10 \mathrm{sccm}$ for $\mathrm{CH}_{4}$, for samples A, B, C, and D, respectively. The working pressure, measured using a MKS Baratron absolute gauge, was maintained around $0.2 \mathrm{~Pa}$, with the help of a throttle valve. The Fe target, equipped with a balanced magnetron, was supplied with an Advanced Energy dc generator (Fort Collins, $\mathrm{CO}$ ), which can deliver a maximal power of $1.5 \mathrm{~kW}$. Target intensity was $I_{\mathrm{T}}=0.2 \mathrm{~A}$. The coatings were prepared using a configuration called triode sputtering system, with a supplementary tungsten filament as second cathode and a ring placed between the substrate and the target as second anode. The intensity of the tungsten filament was $I_{\mathrm{W}}=5 \mathrm{~A}$, the substrate-ring anode distance was $D_{\mathrm{S}-\mathrm{A}}=20 \mathrm{~mm}$, while the anode-target distance was $D_{\mathrm{A}-\mathrm{T}}=60 \mathrm{~mm}$. Time deposition was $7200 \mathrm{~s}$ and the rate deposition was about $1 \mu \mathrm{m} \cdot \mathrm{h}^{-1}$. Therefore, the whole thickness of coatings was about $2 \mu \mathrm{m} .^{16}$

\section{B. Analyzing methods}

Identification of phases was realized by GIXRD using Co $\mathrm{K}_{\alpha}(\lambda=0.17902 \mathrm{~nm})$ radiation with an incidence angle fixed at $0.5^{\circ}$ (INEL CPS120, Artenay, France). SEM was performed with a Philips XL30 SFEG instrument (FEI Company, Eindhoven, The Netherlands), at $5.00 \mathrm{kV}$. Wedge samples for TEM were prepared by polishing the substrate by the classical tripod method ${ }^{17}$ until the sample was thin enough. A subsequent polishing was performed by ion milling (Gatan PIPS, Pleasanton, CA). By this method, only the top of the coating was analyzed by TEM and EELS (plane-view observation). Conventional TEM was performed on a $\mathrm{LaB}_{6}$ Philips CM200 instrument with a voltage of $200 \mathrm{kV}$, and in situ thermal treatment was performed in a Philips CM12 TEM $(120 \mathrm{kV})$ by using a Gatan heating holder. The sample was heated at a rate of $10 \mathrm{~K} / \mathrm{min}$, with stages of $15 \mathrm{~min}$ every $50 \mathrm{~K}$, until the temperature $723 \mathrm{~K}$ was reached.

EELS was carried out with a PEELS 666 Gatan device, coupled to the TEM operating at $120 \mathrm{kV}$, with an entrance aperture of $2 \mathrm{~mm}$, in diffraction mode with chamber length $L=100 \mathrm{~mm}$, convergence semi-angle $\alpha_{c}=6.7 \mathrm{mrad}$, and acceptance semi-angle $\beta=6.55 \mathrm{mrad}$. Two energy dispersion values were chosen, namely

TABLE I. GIXRD, TEM, EELS, and EDS characterization results of Fe-C coatings.

\begin{tabular}{|c|c|c|c|c|c|}
\hline Samples & $D_{\mathrm{CH} 4}(\mathrm{sccm})$ & Identified phases by GIXRD & Identified phases by TEM & Chemical composition (EELS) & $\begin{array}{l}\text { Chemical composition } \\
\text { (EDS from Ref. 15) }\end{array}$ \\
\hline $\mathrm{A}$ & 2.5 & $\varepsilon-\mathrm{Fe}_{3} \mathrm{C}$ & $\varepsilon-\mathrm{Fe}_{3} \mathrm{C}$ & $\mathrm{Fe}_{0.70 \pm 0.07} \mathrm{C}_{0.30} \pm 0.03$ & $\mathrm{Fe}_{0.72} \mathrm{C}_{0.28}$ \\
\hline $\mathrm{B}$ & 5 & $\varepsilon-\mathrm{Fe}_{3} \mathrm{C}$ & $\varepsilon-\mathrm{Fe}_{3} \mathrm{C}$ & $\mathrm{Fe}_{0.64} \pm 0.06 \mathrm{C}_{0.36} \pm 0.03$ & $\mathrm{Fe}_{0.63} \mathrm{C}_{0.37}$ \\
\hline $\mathrm{C}$ & 7.5 & Amorphous-like phase & Nanocomposite film & $\mathrm{Fe}_{0.45} \pm 0.04 \mathrm{C}_{0.55} \pm 0.05$ & $\mathrm{Fe}_{0.51} \mathrm{C}_{0.49}$ \\
\hline $\mathrm{D}$ & 10 & Amorphous-like phase & Nanocomposite film & $\mathrm{Fe}_{0.40} \pm 0.04 \mathrm{C}_{0.60} \pm 0.06$ & $\mathrm{Fe}_{0.37} \mathrm{C}_{0.63}$ \\
\hline
\end{tabular}


0.098 and $0.996 \mathrm{eV} / \mathrm{channel}$, corresponding to the resolution values of 0.7 and $2 \mathrm{eV}$, respectively, with an underheated filament. All spectra were corrected for dark current and detector gain channel-to-channel variation. The low-loss spectra were deconvoluted of the zero-loss peak. To remove the plural inelastic scattering contribution, a Fourier ratio deconvolution procedure (Gatan EL/P software) was applied to each edge (C K and Fe L3L2), after background removal, according to a $\mathrm{Ae}^{-\mathrm{r}}$ power-law. In addition, two reference samples were analyzed with the same procedure, namely an amorphous carbon thin film on a commercial copper grid and a pure iron sample (99.95\%), also prepared by tripod polishing and ion milling.

\section{RESULTS AND DISCUSSION}

\section{A. XRD measurements}

Figure 1 shows XRD patterns of samples A, B, C, and $\mathrm{D}$ (the corresponding results are listed in Table I). The diffraction diagrams of samples A and B exhibit diffraction peaks corresponding to the metastable hexagonal $\varepsilon-\mathrm{Fe}_{3} \mathrm{C}$ phase $^{18}(a=0.4767 \mathrm{~nm}, c=0.4354 \mathrm{~nm}$; SG: $\mathrm{P}_{3} 22$; JCPDS No. 01-089-2005), which is a superstructure of the hexagonal $\varepsilon-\mathrm{Fe}_{2} \mathrm{C}$ phase ${ }^{19,20}(a=0.2754 \mathrm{~nm}$, $c=0.4349 \mathrm{~nm} ; \mathrm{SG}: \mathrm{P}_{3} / \mathrm{mmc}$; JCPDS No. 00-36-1249). The lattice parameters are $a=0.4847 \mathrm{~nm}$ and $c=4.3884$ $\mathrm{nm}$ for sample A, and $a=0.4827 \mathrm{~nm}$ and $c=4.3704 \mathrm{~nm}$ for sample $\mathrm{B}$, respectively, with the same $c / a$ ratio, i.e., 0.905. Variation of lattice parameter values corresponds to an increasing occupation of the octahedral sites by carbon atoms in the hexagonal lattice of the iron atoms. Both patterns of samples C and D present an x-ray amorphous profile. Two corresponding wide peaks are observed at about $2 \theta=50.60^{\circ}$ (lattice spacing $d \approx 0.209$ $\mathrm{nm})$ and $98.52^{\circ}(d \approx 0.118 \mathrm{~nm})$. These distances correspond to the $\{100\}$ and $\{101\}$ planes group of graphite

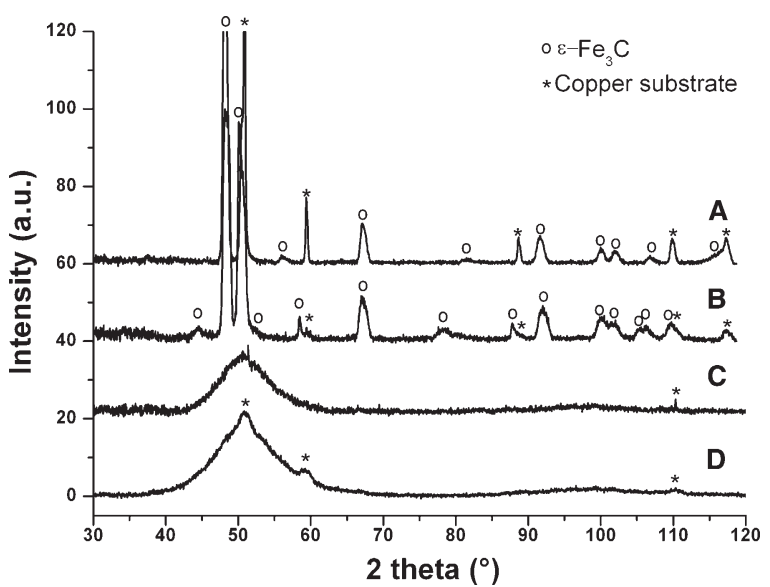

FIG. 1. Grazing incidence XRD patterns (wavelength $\lambda=\mathrm{K}_{\alpha} \mathrm{Co}$ ) of samples $\mathrm{A}$ to $\mathrm{D}$ at incidence $\alpha=0.5^{\circ}(*=$ copper substrate; $\mathbf{o}=$ $\varepsilon-\mathrm{Fe}_{3} \mathrm{C}$ phase). (or band 10 for turbostratic carbon) and to $\{110\} /\{112\}$ group (or band 11), respectively, ${ }^{21}$ and therefore indicate the possible presence of an amorphous carbon phase in the samples. However, the peaks are large enough to also include contributions of other amorphous phases or nanocrystalline $\mathrm{Fe}-\mathrm{C}$ phases.

\section{B. SEM}

Figure 2 displays scanning electron micrographs of surfaces of the samples A to D. Surface of the sample A corresponds to facetted and elongated crystalline grains, with a broad size distribution between 50 and $200 \mathrm{~nm}$. Sample B also presents crystalline grains with a larger size (roughly 100 to $500 \mathrm{~nm}$ ). These grains are more isotropic and possess narrower size distribution than grains in sample A. It should be noted that a poisoning of the iron target has been observed in the presence of $\mathrm{Ar} / \mathrm{CH}_{4}$ gaseous mixture and that the poisoning level seemed to increase with the $\mathrm{CH}_{4}$ flow rate. ${ }^{16}$ This phenomenon is well known in reactive sputtering. It leads to the modification of the discharge properties like the sputter yield, commonly lower in poisoning sputtering mode than in metallic mode. Thus, the surface properties are affected such as deposition rate, chemical composition, grain size, crystallinity, etc. ${ }^{7,22}$ The change in grain size and in grain morphology from sample A to B can therefore be explained by an increase of energy ion bombardment of the growing film leading to the higher mobility of adatoms at the surface. The sample $\mathrm{C}$ presents a glassy dense surface with wide curved domains ( 0.5 to $3 \mu \mathrm{m})$, which corresponds to the amorphous-like state observed by GIXRD. The surface of the sample $\mathrm{D}$ is rougher and presents smaller domains than that of the sample $\mathrm{C}$.

\section{TEM observations}

Bright-field and dark-field micrographs of the coatings A and B are shown on Figs. 3(a)-3(d). The sample A presents grains with an average size of $100 \mathrm{~nm}$, while the sample B possesses the largest grain size, about $400 \mathrm{~nm}$. This difference is also attributed to the poisoning of the target. Electron diffraction patterns (EDPs) of the $\varepsilon-\mathrm{Fe}_{3} \mathrm{C}$ phase along [110] (sample A) and [110] (sample B) zone axes are displayed on Figs. 3(e) and 3(f) (Table I). On Fig. 3(e), the most intense reflections correspond to fundamental reflections of the $\varepsilon-\mathrm{Fe}_{2} \mathrm{C}$ phase while weak spots correspond to the superstructure. Observation of several extinctions in this pattern demonstrates that the compound is nonstochiometric and presents carbon vacancies in its lattice. On Fig. 3(f), arrows indicate weak 001 reflections, with $(1=2 n+1)$, that are not compatible with the $\mathrm{P}_{3} 22$ space group. These reflections are understood as a result of double-diffraction phenomena, which are often encountered during studies of hexagonal lattices by transmission electron diffraction. 


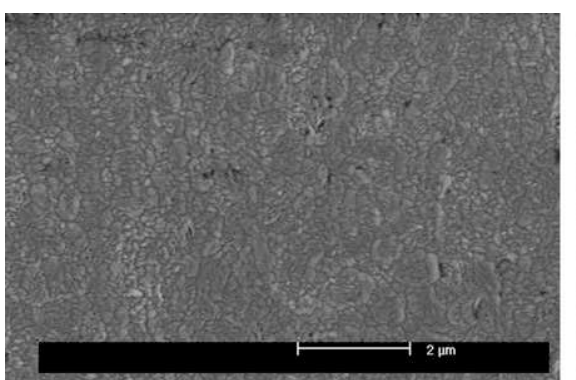

(a)

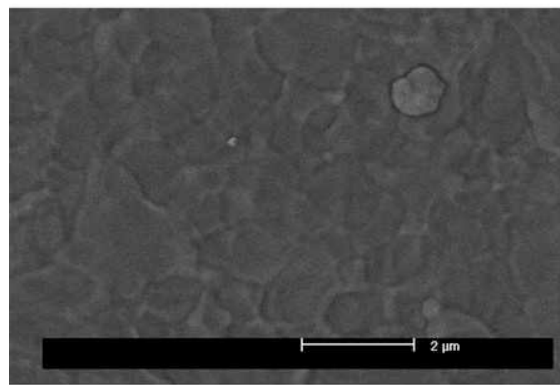

(c)

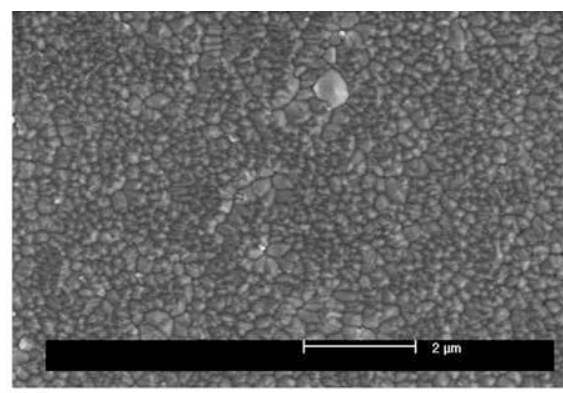

(b)

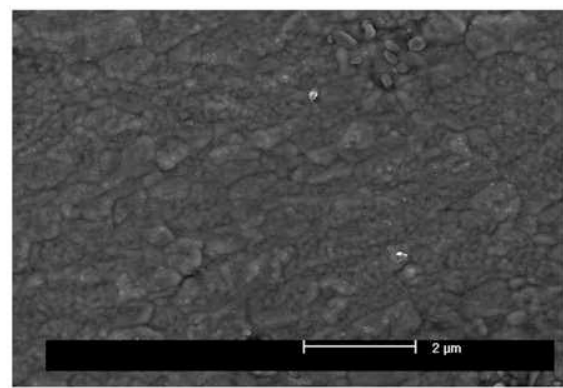

(d)

FIG. 2. Scanning electron micrographs of samples (a) A, (b) B, (c) C, and (d) D.

Bright-field micrographs of the samples $\mathrm{C}$ and $\mathrm{D}$ are shown on Figs. 4(a) and 4(b). These images reveal that the microstructure is constituted of dark nanograins (with an average size of $10 \mathrm{~nm}$ for sample $C$ and $5 \mathrm{~nm}$ for sample D) embedded in a light matrix. The strong contrast difference between grains and matrix indicates that this last one is mainly constituted of carbon while the nanograins are richer in iron. Thickness of matrix between two grains is larger for sample $\mathrm{D}$, corresponding to the higher content of carbon in this coating. In addition, the dark grains are connected in the sample $\mathrm{C}$ while they are mainly disconnected in the sample $\mathrm{D}$, indicating that percolation threshold has not been reached. ${ }^{6,23}$

Figures 4(e) and 4(f) present corresponding EDPs and their diffraction intensity profiles as a function of inverse of lattice spacing $d$. For both samples, the patterns show two diffuse and broad rings characteristic of an amorphous phase, at $d=0.212 \pm 0.05 \mathrm{~nm}$ and $d=0.122 \pm$ $0.05 \mathrm{~nm}$, in agreement with the distances measured by GIXRD (the additional sharp ring is an artefact and corresponds to the image of an upper diaphragm in the microscope). Figures 4(c) and 4(d) show dark-field images of both samples, obtained by selecting the shortest diffusive ring with an objective aperture of the TEM [circled on Figs. 4(e) and 4(f)]. The matrix and the nanograins are both illuminated by this method, the nanograins being brighter, indicating for them either a higher amount of iron and/or a partly crystalline state. Lattice fringe images (Fig. 5) were obtained on both samples. Within the resolution of our instrument, it can be seen that the matrix presents characteristic features of amorphous and poorly crystallized carbon layers with fringes corresponding to bent graphenelike layers [i.e., (002) layers of graphite]. It is expected that diffraction of a graphitic amorphous phase results in a broad peak at $1 /$ day $=2.7-2.8 \mathrm{~nm}^{-1}$ corresponding to the interlayer spacing between graphene layers. For instance, the EDPs of $\mathrm{Fe}-\mathrm{C}$ nanocomposite films in Refs. 6 and 12 exhibit an innermost halo ring corresponding to graphite basal (002) planes. In this study, such a feature is not seen in XRD patterns (at $\theta=27^{\circ}$ $30^{\circ}$ ) and in EDPs. The short stacking ( 2 or 3 layers) of highly faulted and strongly bent graphenelike layers, which partially compose the carbon matrix explains the absence of the (002) peak. Such distortion can enlarge the lattice spacing between subsequent graphitic sheets, introduce large stress, or avoid formation of short-order distances corresponding to interlayer bonds. It has been previously shown by Franklin ${ }^{21}$ that x-ray data of such graphite-like layers, which are well ordered in two dimensions but present disorder in the third direction, exhibit an extremely weak (002) intensity. In Fig. 5, most of the dark nanograins present short-order contrast while some of them present lattice fringes, with periodicities around 0.27 and $0.34 \mathrm{~nm}$. These lattice distances could correspond to several carbides, but not to the $\alpha$-Fe phase. At this point, we can conclude that the nanocomposite films are constituted of disordered and crystalline carbide nanograins embedded in a matrix made of amorphous and poorly crystallized graphenelike carbon.

\section{Electron energy loss spectroscopy results}

Local composition of the $\mathrm{Fe}_{1-x} \mathrm{C}_{x}$ coatings was measured by EELS and compared to previous global 


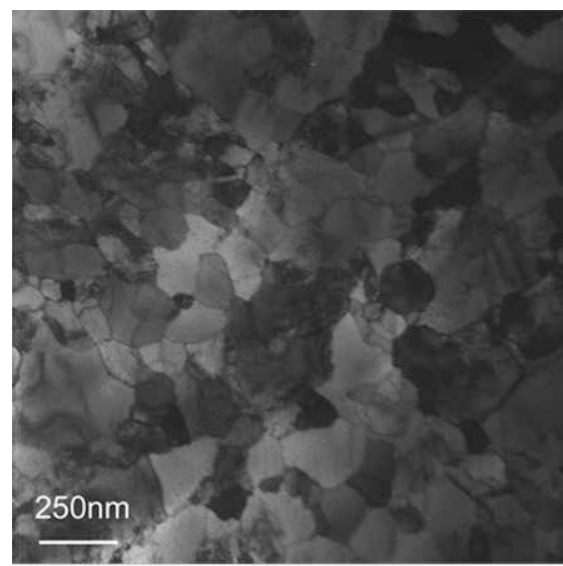

(a)

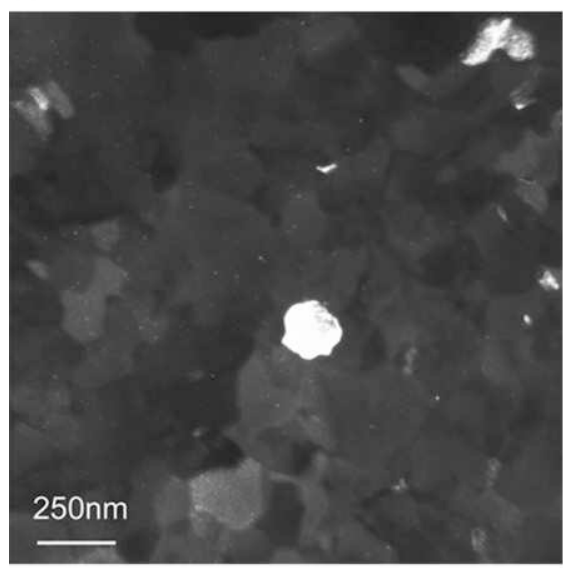

(c)

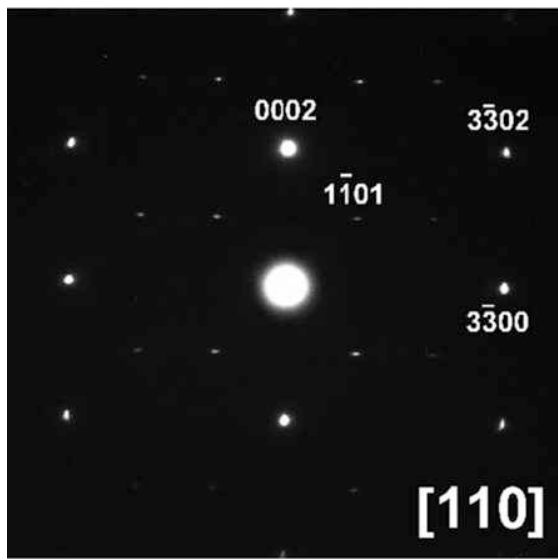

(e)

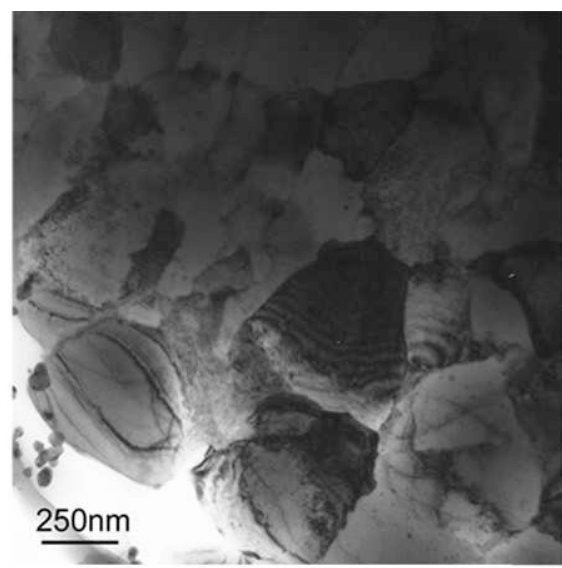

(b)

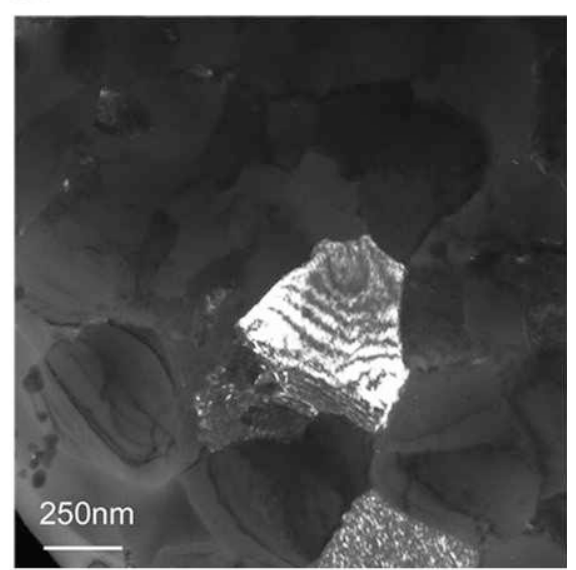

(d)

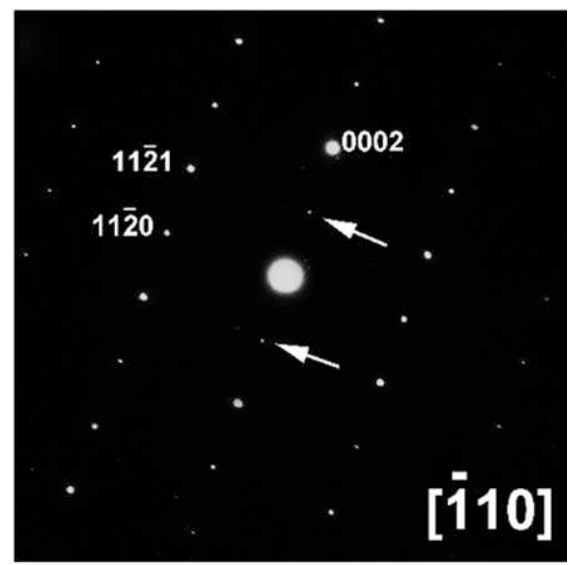

(f)

FIG. 3. Bright-field micrographs of samples (a) A and (b) B. Dark-field micrographs of samples (c) A and (d) B. EDPs of the $\varepsilon$-Fe ${ }_{3} \mathrm{C}$ phase $(a=0.477 \mathrm{~nm}, c=0.4365 \mathrm{~nm})$ along the [110] zone axis $\left[(11 \overline{2} 0)^{*}\right.$ pattern] observed in (e) sample A and along the [ $\left.\overline{1} 10\right]$ zone axis $\left[(\overline{1} 100)^{*}\right.$ pattern] observed in (f) sample B. Arrows indicate reflections arising from double-diffraction phenomena.

measurements by EDS (Table I). These measurements show that the amount of carbon in the coatings increases with the methane partial pressure, as previously reported in Ref. 15. Results from both techniques are similar. A small amount of oxygen was also detected by EELS in sample D at the detection limit of the technique (this amount could be roughly estimated to be below $3 \%$ ).
The presence of oxygen may be due to the tripod preparation, which involves a polishing process under water.

Figure 6 presents low-loss and core-loss spectra for samples A to D, compared to spectra of reference samples, i.e., pure iron and commercial amorphous carbon. In Fig. 6(a), the plasmon peak of the pure iron reference is located at $23.7 \mathrm{eV}$ in agreement with the reported 


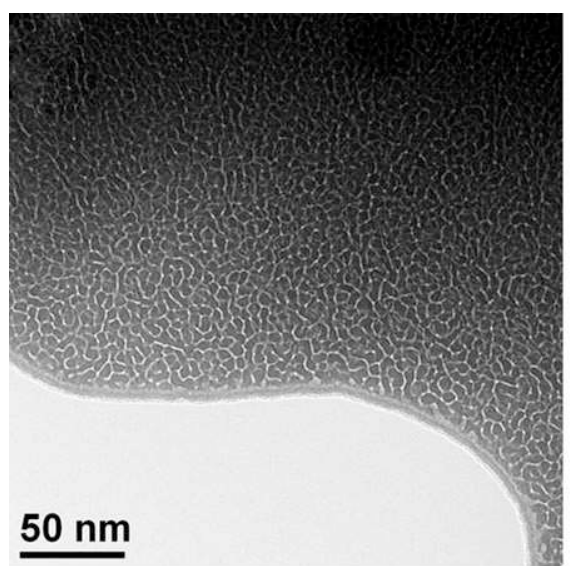

(a)

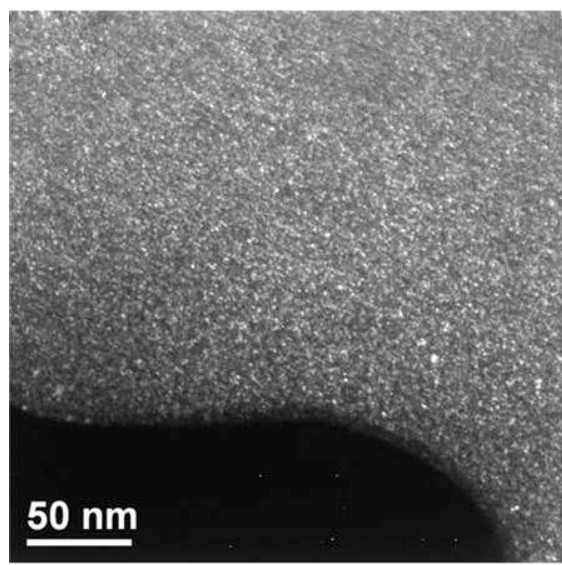

(c)

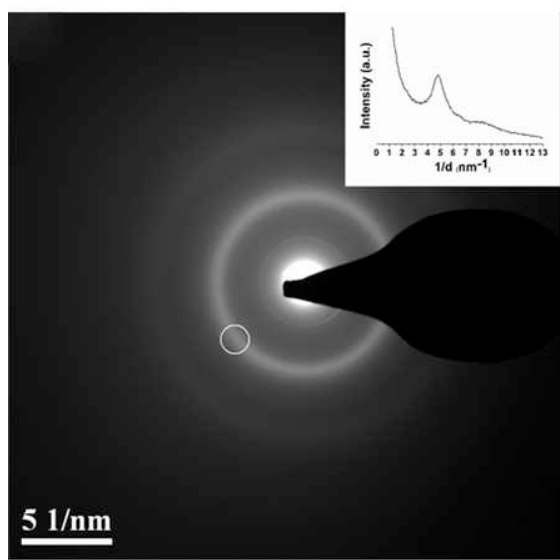

(e)

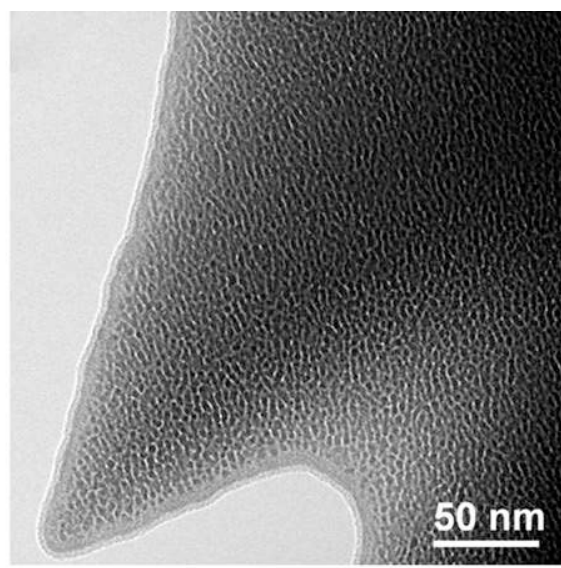

(b)

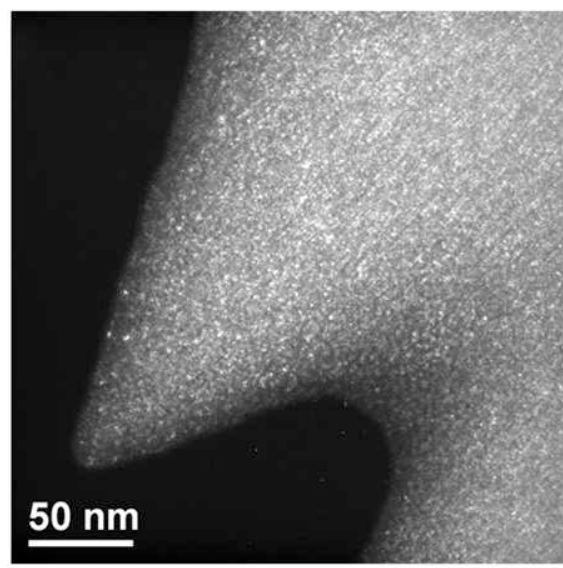

(d)

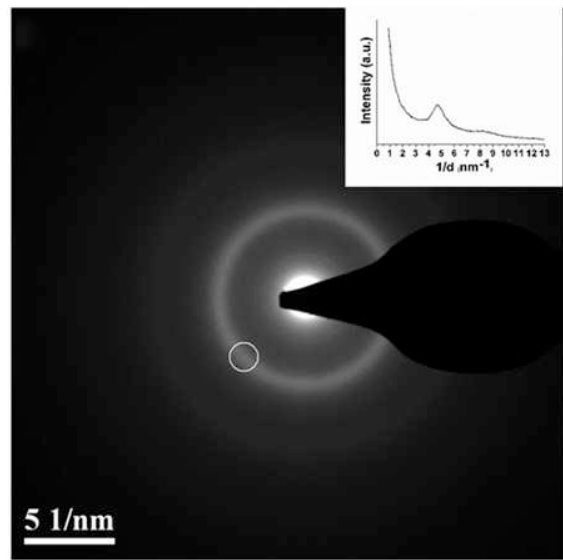

(f)

FIG. 4. (a, b) Bright-field micrographs of samples C and D; (c, d) dark-field micrographs of samples C and D obtained by selecting the first diffusive ring in the EDP; (e,f) corresponding EDPs (open circles correspond to the TEM objective aperture). Insets: electron diffraction intensity profile as a function of $1 /$ day $\left(\mathrm{nm}^{-1}\right)$.

value $24 \mathrm{eV}$ for $\alpha-\mathrm{Fe}^{24} \mathrm{~A}$ weak shoulder appears on the left of the peak at $16.8 \mathrm{eV}$. This feature is the surface plasmon, located at $1 / \sqrt{2}$ times of the bulk plasmons energy and characteristic of a thin specimen. ${ }^{25}$ The Fe $\mathrm{M} 3,2$ edge at $55 \mathrm{eV}$ is clearly visible. The plasmons resonance of the amorphous carbon standard is located at $23.3 \mathrm{eV}$ in agreement with literature results, in which the collective excitation of valence electrons $(\pi+\sigma$ plasmons) appears between 21 to $25 \mathrm{eV}^{26,27}$ This corresponds to an amorphous carbon in which the atoms are mainly $s p^{2}$ bounded. ${ }^{26}$ The broad resonance observed at $5 \mathrm{eV}$ in this spectrum corresponds to the $\pi$ plasmons related to the $\pi-\pi^{*}$ interband transition in graphitic materials. ${ }^{26}$ 


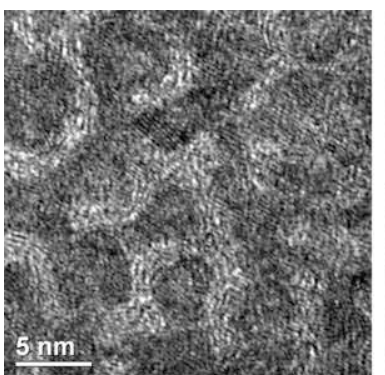

(a)

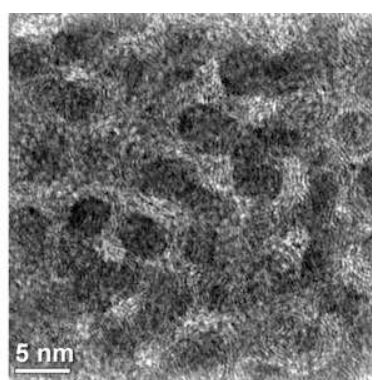

(b)
FIG. 5. Lattice fringes electron micrographs of samples (a) C and (b) D.
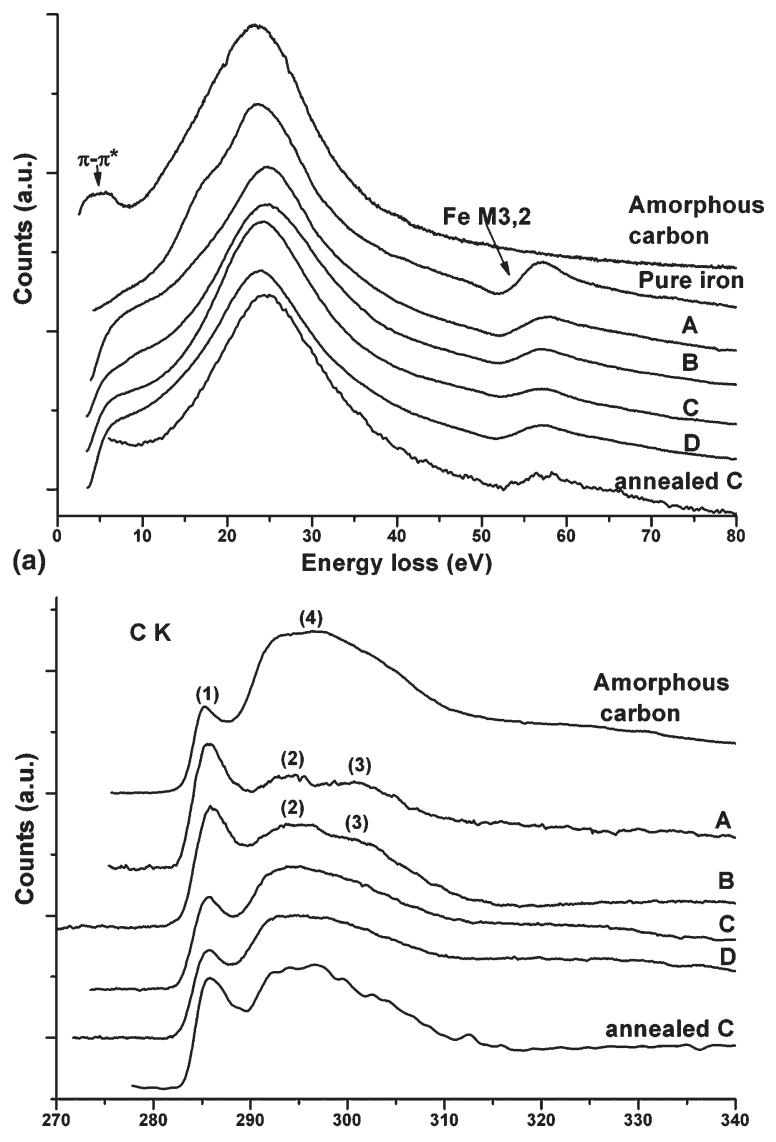

(b)

Energy loss (eV)

FIG. 6. (a) Low-loss EELS spectra of amorphous carbon standard, pure iron standard, $\mathrm{Fe}-\mathrm{C}$ samples $\mathrm{A}$ to $\mathrm{D}$ and annealed sample $\mathrm{C}$; (b) core-loss (C K edge) EELS spectra of amorphous carbon standard, samples A to D and annealed sample $\mathrm{C}$.

Concerning the samples $\mathrm{A}$ and $\mathrm{B}$, both composed of the $\varepsilon-\mathrm{Fe}_{3} \mathrm{C}$ phase, no significant difference with the pure iron spectrum is observed, except in the height of the $\mathrm{Fe}$ M3,2 edge. The relative intensity of this edge is more prominent for these samples than for the samples $\mathrm{C}$ and $\mathrm{D}$, in agreement with the fact that the samples A and B are the richest in iron. Concerning the nanocomposite films, the plasmons resonance is located at $24.2 \mathrm{eV}$ (sample C) and at $23.6 \mathrm{eV}$ (sample D), respectively. In addition, the resonance is more intense for $\mathrm{C}$ than for $\mathrm{D}$. The position of this resonance does not correspond to that of the graphite (located at $27 \mathrm{eV}$ according to literature), ${ }^{26}$ but may correspond to amorphous carbon or to structures made of curved graphene sheets. ${ }^{28,29}$ No peaks relative to the $\pi-\pi^{*}$ bands transition is observed in spectra of sample $\mathrm{C}$ and $\mathrm{D}$, although graphenelike layers were observed by TEM. It was demonstrated that due to the anisotropy of the graphite, the low-loss spectrum of this structure change as a function of the $c$-axis orientation regarding the electron beam. ${ }^{28,30}$ In particular, when the graphene layers are parallel to the beam, intensity of the interband resonance strongly decreases and the plasmons resonance is moved toward the lower energy values. The same behavior occurs for objects made of curved and defected graphene layers, as carbon-filled fullerenes, nanotubes, nanocones, etc., which present different spectra for the same unique object as a function of the zone, which is impacted by the beam. ${ }^{28,29}$ Nevertheless, when a large number of such randomly oriented objects are probed simultaneously, the mean spectrum presents the $\pi-\pi^{*}$ peak, as can be seen in Ref. 30 for nano-onions. Therefore, the absence of this peak in spectra of nanocomposite samples, together with the slight differences in position and height of the $(\pi+\sigma)$ plasmons peak between $\mathrm{C}$ and $\mathrm{D}$, suggests a possible anisotropy of the C-rich domains observed in Fig. 5, with the graphenelike layers mainly parallel to the electron beam. Elongation of carbon domains of a nanocomposite $\mathrm{Fe}-\mathrm{C}$ coating was previously evidenced by Babonneau et al. $^{6}$ and considered the result of a columnar growth. Nevertheless, interpretation of low-loss spectra is limited because the samples are composite materials. In addition, no information concerning the iron-rich nanograins are available in these spectra.

Figure 6(b) shows the $\mathrm{C} \mathrm{K}$ edge for the amorphous carbon standard and the samples A to D. The edge is characterized by a fine peak, noted (1) for all samples. This resonance at $284 \mathrm{eV}$ results from transitions $1 s-\pi^{*}$ and is characteristic of $s p$ and $s p 2$ bonds. ${ }^{31,32}$ Post-edge, energy-loss near-edge structures (ELNES) of the samples A and B are composed of two contributions (2) and (3), located at 8 and $15 \mathrm{eV}$ from the edge, respectively. It is well known that the ELNES often exhibit a structure specific to the nearest neighbor environment of the atom undergoing excitation (also called coordination fingerprint). ${ }^{33}$ In samples $\mathrm{A}$ and $\mathrm{B}$, carbon atoms are located in octahedral sites of iron carbides. Post-edge contributions correspond to a fingerprint similar to that found for $\mathrm{N} \mathrm{K}$ edges in isostructural hexagonal transition metal nitrides, ${ }^{34}$ such as hexagonal $\mathrm{Cr}_{2} \mathrm{~N}, \mathrm{~V}_{2} \mathrm{~N}$ (both isostructural to $\varepsilon-\mathrm{Fe}_{2}-{ }_{3} \mathrm{C}$ ), ${ }^{35,36}$ and $\varepsilon-\mathrm{Ti}_{2} \mathrm{~N}$ (structurally related to $\varepsilon$-phase). ${ }^{37}$ ELNES of these 3 nitrides are similar to the signal presented in Fig. 6(b). In particular, calculated spectra in Ref. 35 show the presence of the post-edge features at 7 and $14 \mathrm{eV}$ behind the edge. 
The $1 s-\pi^{*}$ peaks in spectra of the samples $\mathrm{C}$ and $\mathrm{D}$ are wider, while their magnitudes decrease. In addition, the ELNES structure is a single broad contribution (4), whose intensity, relatively to those of the edge is more and more important. For carbon materials, this wide peak at $295 \mathrm{eV}$ results from transitions $1 s-\sigma^{*} .{ }^{26,31,32,38}$ The shape of the ELNES structures in spectra of samples C and D is similar to that of the amorphous carbon standard, and different than that of the graphite. ${ }^{30,38}$ The height of the $\sigma^{*}$ peak relative to that of the $\pi^{*}$ edge demonstrates that the ratio $s p 2 / s p 3$ bonds of the carbon material in the samples $\mathrm{C}$ and $\mathrm{D}$ is larger than in the standard. It is interesting to note that for carbon materials made of curved graphene layers, the sigma bonds are not purely of the $s p 2$ type, but between $s p 2$ and $s p 3$ bonds, ${ }^{38}$ while their spectrum could be similar to that of the amorphous phase. ${ }^{39}$ Therefore, the ELNES structures of the samples C and D correspond either to amorphous carbon or to poorly crystallized graphene or to a mixture of both, as observed by TEM.

Concerning the Fe L3L2 edge, no significant difference has been observed between spectra of the iron standard and the $\mathrm{Fe}-\mathrm{C}$ samples. Therefore, these results are not presented here. None of these spectra present characteristic features of iron oxidation (like large white lineintensity ratio L3/L2 or presence of broad peak at $37 \mathrm{eV}$ from the edge). ${ }^{40-42}$

\section{E. In situ annealing treatment results}

In situ annealing treatments in the TEM were undertaken to evaluate thermal stability of the nanocomposite $\mathrm{Fe}-\mathrm{C}$ films and to identify the transformation products. Crystallization study of a disordered solid state is a way to discover new crystalline arrangements and this approach was already used in the Fe-C system. ${ }^{43-45}$ Furthermore, several new iron carbides were recently reported. ${ }^{46-48}$ Because of the presence of oxygen in the sample $\mathrm{D}$, one of its crystallization products was the $\mathrm{Fe}_{3} \mathrm{O}_{4}$ oxide. Consequently, results of this experiment are not shown here. For the sample $\mathrm{C}$, structural changes of the nanocomposite into large crystalline grains, with a size of about $0.5 \mu \mathrm{m}$, started around $523 \mathrm{~K}$. The transformation was accomplished at $723 \mathrm{~K}$.

This grain size is large enough to allow observation of the same grain in reciprocal space along several zone axes in microdiffraction conditions (i.e., with an almost parallel beam and a small probe size). Several grains have been analyzed and at least three crystalline structures have been identified in the same sample.

Figure 7 shows EDPs of these crystalline phases. The first one is the orthorhombic $\theta-\mathrm{Fe}_{3} \mathrm{C}$ (SG: Pnma; $a=$ $0.5089 \mathrm{~nm}, b=0.67433 \mathrm{~nm}, c=0.45235 \mathrm{~nm}$ ). Figure 7(a) presents the EDP along the [110] zone axis of $\theta-\mathrm{Fe}_{3} \mathrm{C}$. The second observed structure is the orthorhombic $\mathrm{Fe}_{7} \mathrm{C}_{3}$ phase [Fig. 7(b): EDP along the [021] zone axis]. The

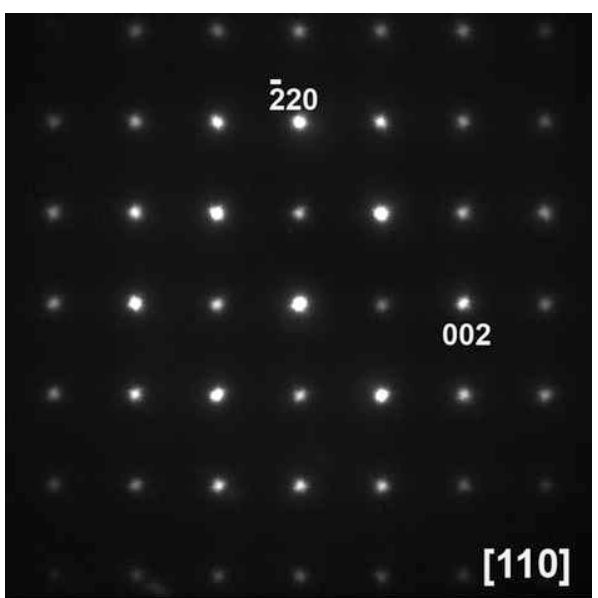

(a)

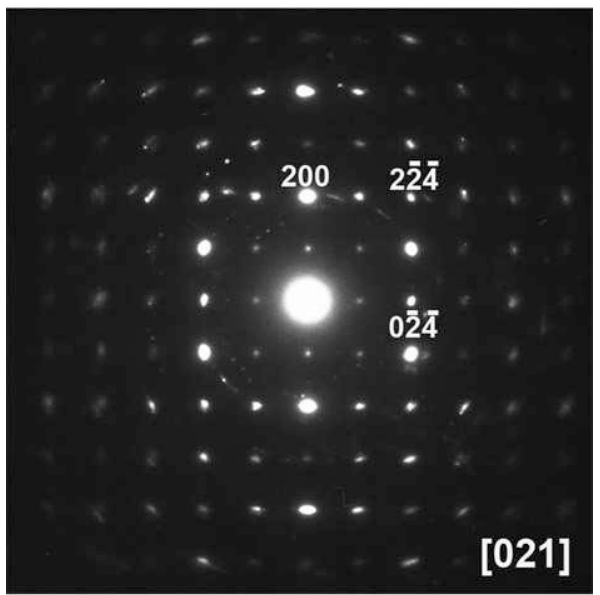

(b)

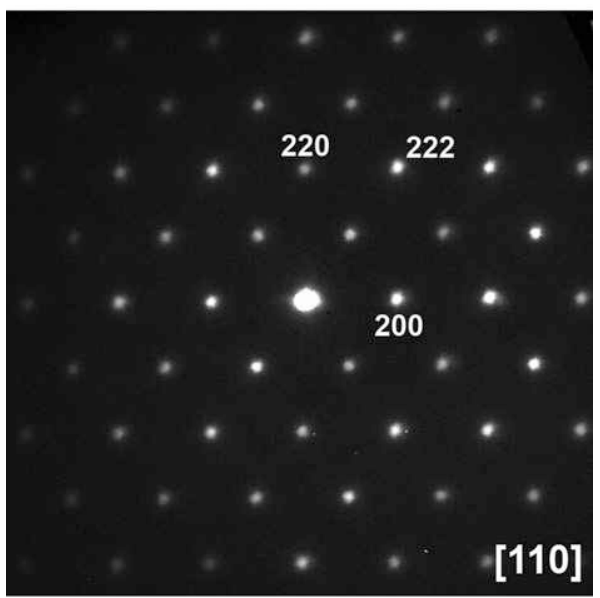

(c)

FIG. 7. (a) EDPs of the $\theta-\mathrm{Fe}_{3} \mathrm{C}$ phase along the [110] zone axis, (b) of the orthorhombic $\mathrm{Fe}_{7} \mathrm{C}_{3}$ phase along the [021] zone axis, (c) of a new fcc carbide ( $a=0.784 \mathrm{~nm}$, possibly related to the $\tau_{2}-\mathrm{Fe}_{2} \mathrm{C}_{7}$ phase) along the $[110]$ zone axis.

lattice parameters of this phase are $a=0.453 \mathrm{~nm}, b=$ $0.689 \mathrm{~nm}$, and $c=1.191 \mathrm{~nm}$ and its space group is Pnma. In these two carbides, the carbon atom coordination is prismatic. These results are in agreement with previous 
studies. ${ }^{43-45}$ Finally, EDPs of the third crystallization product were indexed using a face-centered-cubic (fcc) cell with $a=0.784 \mathrm{~nm}$. EDP along [110] zone axis of this phase is shown on Fig. 7(c). From the lattice constant and Bravais lattice viewpoint, it is similar to the carbon-rich carbide called $\tau_{2}-\mathrm{Fe}_{2} \mathrm{C}_{7}$, one of the two new iron carbides discovered in 1995 by Komekyu et al. ${ }^{46}$ by heating a mixture of iron and carbon powders in a stream of hydrocarbon gas at $1870 \mathrm{~K}$. Moreover, the presence of a carbonrich compound with the two iron-rich $\theta-\mathrm{Fe}_{3} \mathrm{C}$ and $\mathrm{Fe}_{7} \mathrm{C}_{3}$ carbides allows preservation of the composition of the sample. Therefore, this new fcc phase is possibly related to the $\tau_{2}-\mathrm{Fe}_{2} \mathrm{C}_{7}$ carbide. The two lattice fringe measurements previously mentioned in Fig. $5(\approx 0.24$ and $0.274 \mathrm{~nm})$ can be assigned to the $\{220\}$ and $\{311\}$ interplanar distances of this new fcc phase. This phase was possibly already present in nanograins before the thermal treatment. EELS was also performed on the annealed sample C. Only C K and Fe L3L2 edges are present in the spectrum registered with a dispersion value of $\sim 1 \mathrm{eV} /$ channel (not shown here), which means that no oxygen has been detected (at $532 \mathrm{eV}$ ) in the coating after annealing. Global chemical composition is $\mathrm{Fe}_{0.47} \pm 0.03 \mathrm{C}_{0.53} \pm 0.03$. All other spectra are presented in Fig. 6, to facilitate comparison with as-sputtered coatings. The plasmons resonance is located at $24.7 \mathrm{eV}$ in the low-loss spectrum, which corresponds to a shift of $0.5 \mathrm{eV}$ toward high energy values, compared to the sample $\mathrm{C}$ before annealing. This shift is expected since the annealed coating is constituted of carbides. The $\mathrm{C}$ K edge is presented in Fig. 6(b). This contribution is different from both crystalline $\varepsilon-\mathrm{Fe}_{3} \mathrm{C}$ and nanocomposite structures. The $1 s-\pi^{*}$ resonance is broader and its intensity is smaller than the ELNES intensity, as for the nanocomposite structure. In the ELNES signal, several characteristic features are present. However, the present sample is a mixture of carbides, with possibly different carbon environments (prismatic coordination of carbon atoms in $\theta-\mathrm{Fe}_{3} \mathrm{C}$ and $\mathrm{Fe}_{7} \mathrm{C}_{3}$ phases, while iron atoms are octahedrally coordinated in $\tau_{2}-\mathrm{Fe}_{2} \mathrm{C}_{7}$, according to the structural model of this carbide, which was proposed from electron diffraction intensities ${ }^{46}$ and if the new phase is the $\tau_{2}-\mathrm{Fe}_{2} \mathrm{C}_{7}$ compound), the corresponding spectrum is therefore more complex than previous ones. This ELNES structure should contain fingerprints of $\mathrm{Fe}_{7} \mathrm{C}_{3}$ and cementite-type carbides but it was difficult to compare with those found by previous studies for $(\mathrm{Cr}, \mathrm{Fe})_{7} \mathrm{C}_{3}{ }^{34}$ and the cementite phase, ${ }^{49}$ respectively. In all works, the $\pi^{*}$ edge intensity is higher than the ELNES intensity. Concerning the Fe edge (spectrum not shown), no oxidation feature is observed.

\section{CONCLUSION}

$\mathrm{Fe}_{1-x} \mathrm{C}_{x}$ coatings have been prepared by reactive triode-magnetron sputtering. The surface of these coatings has been investigated by GIXRD, SEM, TEM, and EELS. This study has demonstrated the ability to produce iron-carbon films by reactive sputtering of an iron target in partial methane atmosphere. Control of the methane flux allows the formation of more and less carbon-rich materials:

(1) iron carbide, in which the carbon atoms are in octahedral coordination. Electron low-loss and core-loss energy spectra have been investigated, and compared to that of amorphous carbon and pure iron standards, and to isostructural transition metal nitrides.

(2) nanocomposite microstructure consisting in disordered and crystalline carbide nanograins embedded in an amorphous and poorly crystallized $s p 2 / s p 3$ carbon matrix. The graphenelike layers in the nanocomposite structures are strongly bent, have no tendency to parallel stacking, and are mainly parallel to the electron beam, indicating a columnar-like growth. The percolation threshold of the iron-rich grains is almost reached in the richest carbon coating $\left(\mathrm{Fe}_{0.40} \pm 0.03 \mathrm{C}_{0.60} \pm 0.03\right)$.

The crystallization products of the nanocomposite $\mathrm{Fe}_{0.45} \pm 0.03 \mathrm{C}_{0.55} \pm 0.03$ film are the known $\theta-\mathrm{Fe}_{3} \mathrm{C}$ and $\mathrm{Fe}_{7} \mathrm{C}_{3}$ compounds, in which the carbon atoms are in prismatic coordination, and a new fcc carbide $(a=$ $0.784 \mathrm{~nm}$ ), possibly related to the C-rich cubic $\tau_{2}-\mathrm{Fe}_{2} \mathrm{C}_{7}$ phase, in which the iron atoms are octahedrally coordinated. ${ }^{46}$

The results we obtained show the wide variety of materials that can be synthesized by reactive sputtering by varying only one elaboration parameter and suggest that it would be interesting to study the effects of other determining elaboration parameters, such as substrate temperature or gas reactivity, to produce either new carbides or to control composition and microstructure of nanocomposite films. Indeed, control of the size and of the insulation of individual particles of metals showing a low solubility for carbon (as Fe, Co, Ni, Cr, Au, Pt, Ag, etc.) and embedded in a carbon matrix is crucial for their mechanical, tribological, magnetic, and electronic properties. ${ }^{23,50-52}$ Reactive sputtering is nowadays an industrial process, the potential applications are high-density magnetic recording media, with magnetic $\mathrm{Fe}$, $\mathrm{Co}$, or $\mathrm{Ni}$ particles acting as granular materials, protective coatings against wear or hard cutting tools. Further investigations on properties of the new carbon-rich carbide are required to define a possible application of this material.

This study will be followed by the description of the effects of the poisoning of the target and the characterization of the coatings in cross-sectional view.

\section{ACKNOWLEDGMENTS}

The authors gratefully acknowledge Tran Huu Loi for his technical assistance and Patrick Weisbecker for fruitful discussions. 


\section{REFERENCES}

1. R.W.K. Honeycombe and H.K.D.H. Bhadeshia: Steels: Microstructure and Properties, 2nd ed. (Edward Arnold Publishers, London, UK, 1995).

2. A. Neckel: The Physics and Chemistry of Carbides, Nitrides and Borides, edited by R. Freer (Kluwer, Dordrecht, The Netherlands, 1990), p. 458.

3. S. Tajima and S. Hirano: Synthesis and properties of $\mathrm{Fe}_{3} \mathrm{C}$ film by RF magnetron sputtering. J. Mater. Sci. 28, 2715 (1993).

4. Y.H. Lee, T.C. Han, and J.C.A. Huang: Magnetic properties of $\mathrm{Fe}_{3} \mathrm{C}$ nanograins embedded in carbon matrix. J. Appl. Phys. 93, 8462 (2003).

5. Y. Lee, T. Han, and C.S. Wur: Resistance and magnetoresistance of annealed amorphous carbon films containing $\mathrm{Fe}_{3} \mathrm{C}$ nanograins. J. Magn. Magn. Mater. 272-276, 2178 (2004).

6. D. Babonneau, J. Briatico, F. Petroff, T. Cabioc'h, and A. Naudon: Structural and magnetic properties of $\mathrm{Fe}_{x} \mathrm{C}_{1-x}$ nanocomposite thin films. J. Appl. Phys. 87, 3432 (2000).

7. I. Safi: Recent aspects concerning DC reactive magnetron sputtering of thin films: A review. Surf. Coat. Technol. 127, 203 (2000).

8. R. Sakai and Y. Shimada: Coercive forces and magnetorestriction of $\mathrm{Fe}-\mathrm{C}$ films deposited on $\mathrm{ZnO}$ substrates. Phys. Status Solidi A 113, K131 (1989).

9. V.S. Zhigalov, O.A. Bayukov, R.S. Iskhakov, and G.I. Frolov: Phase transformations in FeC films. Phys. Met. Metall. 93, 289 (2002).

10. N. Kazama, N. Heiman, and R.L. White: Magnetic properties of amorphous FeC thin films. J. Appl. Phys. 49, 1706 (1978).

11. E. Bauer-Grosse and G. Le Caer: Structural evolution of sputtered amorphous $\mathrm{Fe}_{1-x} \mathrm{C}_{x}$ films for $0.19 \leq x \leq 0.49$. Philos. Mag. B 56, 485 (1987).

12. D. Babonneau, T. Cabioc'h, M.F. Denanot, and A. Naudon: Microstructural study of a C-Fe alloy synthesized by ion-beam sputtering co-deposition. Appl. Phys. Lett. 74, 800 (1999).

13. Y.H. Lee, T.C. Han, J.C.A. Huang, and C.R. Lin: Analysis of microstructure of magnetic $\mathrm{Fe}_{3} \mathrm{C}$ nanograins embedded in amorphous carbon films. J. Appl. Phys. 94, 1975 (2003).

14. C. Corbella, E. Bertran, M.C. Polo, E. Pascual, and J.L. Andújar: Structural effects of nanocomposite films of amorphous carbon and metal deposited by pulsed-DC reactive magnetron sputtering. Diamond Relat. Mater. 16, 1828 (2007).

15. I. Jouanny, A. Billard, T.H. Loi, V. Demange, and E. Bauer-Grosse: Sputtered $\mathrm{Fe}_{1-x}\left(\mathrm{~N}_{1-y} \mathrm{C}_{y}\right)_{x}$ films obtained in various $\left(\mathrm{Ar}-\mathrm{N}_{2}-\mathrm{CH}_{4}\right)$ reactive plasmas. Surf. Coat. Technol. 200, 1690 (2005).

16. I. Jouanny: Study of iron carbides, nitrides and carbonitrides prepared by magnetron sputtering. Ph.D. Thesis (Institut National Polytechnique de Lorraine, Nancy, France, 2006. http://www.scd. inpl-nancy.fr/theses/2006_JOUANNY_I.pdf).

17. J. Benedict, R. Anderson, and S.J. Klepeis: Recent developments in the use of the tripod polisher for TEM specimen preparation, in Specimen Preparation for Transmission Electron Microscopy of Materials III, edited by R. Anderson, B. Tracy, and J. Bravman (Mater. Res. Symp. Proc. 254, Pittsburgh, PA, 1992), p. 121.

18. H.L. Yakel: Crystal structures of stable and metastable iron containing carbides. Int. Met. Rev. 30, 17 (1985).

19. L.J.E. Hofer, E.M. Cohn, and W.C. Peebles: The modifications of the carbide $\mathrm{Fe}_{2} \mathrm{C}$ : Their properties and identification. J. Am. Chem. Soc. 71, 189 (1949).

20. K.H. Jack: Results of further $\mathrm{x}$-ray structural investigations of the iron carbon and iron nitrogen systems and of related interstitial alloys. Acta Crystallogr. 3, 392 (1950).

21. R.E. Franklin: The interpretation of diffuse x-ray diagrams of carbon. Acta Crystallogr. 3, 107 (1950).
22. J. Musil, P. Baroch, J. Vlček, K.H. Nam, and J.G. Han: Reactive sputtering magnetron of thin films: Present status and trends. Thin Solid Films 475, 208 (2005).

23. K.I. Schiffmann, M. Fryda, G. Goerigk, R. Lauer, P. Hinze, and A. Bulack: Sizes and distances of metal clusters in Au-, Pt-, W- and Fe-containing diamond-like carbon hard coatings: A comparative study by small angle $\mathrm{x}$-ray scattering, wide angle $\mathrm{x}$-ray diffraction, transmission electron microscopy and scanning tunnelling microscopy. Thin Solid Films 347, 60 (1999).

24. D.L. Misell and A.J. Atkins: Electron-energy loss spectra for first transition series. Philos. Mag. 27, 95 (1973).

25. R.F. Egerton: Electron Energy Loss Spectroscopy in the Electron Microscope (Plenum Press, New York, 1996).

26. J. Fink: Recent developments in energy-loss spectroscopy. $A d v$. Electron. Electron Phys. 75, 121 (1989).

27. P. Kovarik, E.B.D. Bourdon, and R.H. Prince: Electron-energyloss characterization of laser-deposited $a-\mathrm{C}, a-\mathrm{C}: \mathrm{H}$, and diamond films. Phys. Rev. B 48, 12123 (1993).

28. T. Stöckli, J.M. Bonard, A. Châtelain, Z.L. Wang, and P. Stadelmann: Plasmon excitations in graphitic carbon spheres measured by EELS. Phys. Rev. B 61, 5751 (2000).

29. L. Henrard, O. Stephan, and C. Colliex: Electron energy loss study of plasmons excitations in curved carbon network. Synth. Met. 103, 2502 (1999).

30. L. Joly-Pottuz, B. Vacher, N. Ohmae, J.M. Martin, and T. Epicier: Anti-wear and friction reducing mechanisms of carbon nanoonions as lubricant additives. Tribol. Lett. 30, 69 (2008).

31. H.K. Schmid: Phase identification in carbon and BN systems by EELS. Microsc. Microanal. Microstruct. 6, 99 (1995).

32. S.R.P. Silva and V. Stolojan: Electron energy loss spectroscopy of carbonaceous materials. Thin Solid Films 488, 283 (2005).

33. R. Brydson, H. Sauer, W. Engel, and E. Zeitler: EELS as a fingerprint of the chemical coordination of light-elements. Microsc. Microanal. Microstruct. 2, 159 (1991).

34. M.M. Disko: Electron energy loss fine structure of carbides and nitrides, in Materials Problem Solving with the Transmission Electron Microscope, edited by L.W. Hobbs, K.H. Westmacott, and D.B. Williams (Mater. Res. Soc. Symp. Proc. 62, Pittsburgh, PA, 1986), p. 129.

35. C. Mitterbauer, C. Hébert, G. Kothleitner, F. Hofer, P. Schattschneider, and H.W. Zandbergen: Electron energy lossnear edge structure as a fingerprint for identifying chromium nitrides. Solid State Commun. 130, 209 (2004).

36. F. Hofer, P. Warbichler, A. Scott, R. Brydson, I. Galesic, and B. Kolbesen: Electron energy loss near edge structure on the nitrogen K-edge in vanadium nitrides. J. Microsc. Oxford 204, 166 (2001).

37. Y. Kihn, C. Mirguet, and L. Calmels: EELS studies of Ti-bearing materials and ab initio calculations. J. Electron Spectrosc. Relat. Phenom. 143, 117 (2005)

38. A.L. Hamon, J. Verbeeck, D. Schryvers, J. Benedikt, and R.M.C.M v.d. Sanden: ELNES study of carbon K-edge spectra of plasma deposited carbon films. J. Mater. Chem. 14, 2030 (2004).

39. S. Tomita, M. Fujii, S. Hayashi, and K. Yamamoto: Electron energy-loss spectroscopy of carbon onions. Chem. Phys. Lett. 305, 225 (1999).

40. C. Colliex, T. Manoubi, and C. Ortiz: Electron-energy-loss-spectroscopy near-edge fine-structures in the iron-oxygen system. Phys. Rev. B 44, 11402 (1991).

41. F. Wang, M. Malac, and R.F. Egerton: Energy-loss near-edge fine structures of iron nanoparticles. Micron. 37, 316 (2006).

42. F. Wang, M. Malac, and R.F. Egerton: Alternative methods of identifying the oxidation of metallic nanoparticles embedded in a matrix. Micron. 38, 371 (2007). 
43. E. Bauer-Grosse, C. Frantz, G. Le Caer, and N. Heiman: Formation of $\mathrm{Fe}_{7} \mathrm{C}_{3}$ and $\mathrm{Fe}_{5} \mathrm{C}_{2}$ type metastable carbides during the crystallization of an amorphous $\mathrm{Fe}_{75} \mathrm{C}_{25}$ alloy. J. Non-Cryst. Solids 44, 277 (1981).

44. E. Bauer-Grosse and G. Le Caer: Crystallisation of amorphous $\mathrm{Fe}_{1-x} \mathrm{C}_{x}$ alloys $(0.30 \leq x \leq 0.32)$ and chemical twinning. J. Phys. F: Met. Phys. 16, 399 (1986).

45. E. Bauer-Grosse and G. Le Caer: Structural model for commensurate and non-periodic carbides formed by crystallization of amorphous iron-carbon alloys. Mater. Sci. Eng. 97, 273 (1988).

46. T. Komekyu, T. Matsumoto, and S. Nagakura: Electron diffraction structure analysis of two kinds of new iron carbides with high carbon content. Mater. Trans., JIM 36, 1332 (1995).

47. Y. Kimura and C. Kaito: Formation of new carbides with diamond structure from carbon film containing transition metal. Thin Solid Films 476, 65 (2005).
48. S. Cusenza, M. Seibt, and P. Schaaf: Deposition and properties of high-carbon iron films. Appl. Surf. Sci. 254, 955 (2007).

49. K. He, A. Brown, R. Brydson, and D.V. Edmonds: Analytical electron microscope study of the dissolution of the $\mathrm{Fe}_{3} \mathrm{C}$ iron carbide phase (cementite) during a graphitisation anneal of carbon steel. J. Mater. Sci. 41, 5235 (2006)

50. T. Hayashi, S. Hirono, M. Tomita, and S. Umemura: Magnetic thin films of cobalt nanocrystals encapsulated in graphite-like carbon. Nature 381, 772 (1996).

51. D. Babonneau, T. Cabioc'h, A. Naudon, J.C. Girard, and M.F. Denanot: Silver nanoparticles encapsulated in carbon cages obtained by co-sputtering of the metal and graphite. Surf. Sci. 409, 358 (1998).

52. G. Gassner, J. Patscheider, P.H. Mayrhofer, E. Hegedus, L. Tóth, I. Kovacs, B. Pécs, V. Srot, Ch. Scheu, and C. Mitterer: Structure of sputtered nanocomposite $\mathrm{CrC}_{x} / a-\mathrm{C}: \mathrm{H}$ thin films. J. Vac. Sci. Technol., B 24, 1837 (2006). 